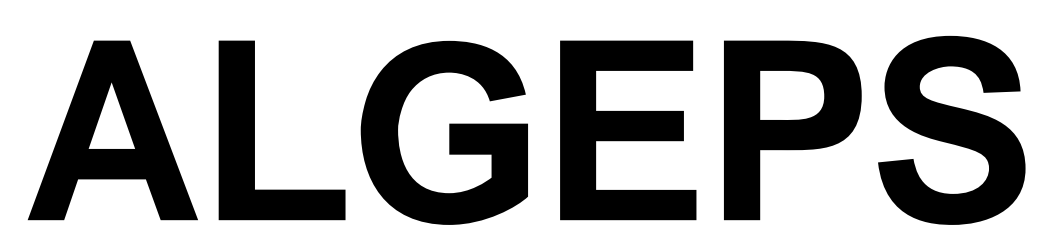

REVISTA DE GEOLOGIA, SÈRIE B no 629 - Maig del 2013

ISSN $1132-7014$

D.L.B. 28.178 - 92

10 pàgines

\title{
RECORREGUT GEOLÒGIC I MINERALÒGIC PER LA COMARCA DE LA TERRA ALTA: DES D'HORTA DE SANT JOAN A BOT
}

Josep M. Mata-Perelló i Joaquim Sanz Balagué 


\section{RECORREGUT GEOLÒGIC I MINERALÒGIC PER LA COMARCA DE LA TERRA ALTA: DES D'HORTA DE SANT JOAN A BOT}

Per Josep M. MATA-PERELLÓ i Joaquim SANZ BALAGUÉ

\section{ADVERTIMENTS PREVIS}

Com en altres recorreguts de RECERCA GEOLÒGICA I MINERALÒGICA ..., si es disposa del temps suficient, poden efectuar-se passant per totes les parades i filloles. En cas contrari, recomanem prescindir de les anomenades PARADES - CONDICIONALS.

També recomanem de cercar la informació més adient, sobre els trams a recórrer mitjançant camins de terra, o de pista. Precisament, en aquest itinerari, hi ha alguns trajectes d'aproximació cap a les mines, que haurem de fer per camins de terra en irregular estat de conservació.

Per d'altra banda, recomanem tenir una cura extrema de la NATURA, evitant qualsevol forma d'agressió sobre ella, o de fer-n'hi un mal ús del que en ofereix la nostra mare Terra.

\section{BREU INTRODUCCIÓ}

En aquesta ocasió, el recorregut del present itinerari discorrerà per una zona en la qual conflueixen tres unitats geològiques netament diferenciades: la Depressió Geològica de l'Ebre, la Serralada Prelitoral Catalana (del Sistema Mediterrani), i la Serralada Ibèrica.

Així, en quasi tot el recorregut, entre Horta de Sant Joan i Bot Gandesa, el trajecte transitarà per la primera unitat geològica esmentada, (per la Depressió Geològica de $l^{\prime}$ Ebre), entre afloraments de materials cenozoics, generalment detrítics, de l'Eocè i de l'Oligocè. Encara que molt a prop dels afloraments dels materials mesozoics de la Serralada Prelitoral Catalana (del Sistema Mediterrani), que no arribarem a tallar.

Tot i així, a l'inici del recorregut, transitarem entre la zona de contacte d'aquesta depressió amb els relleus de la Serralada Ibèrica.

Finalment, cal dir, que el recorregut de l'itinerari, discorrerà per una de les comarques de la Regió de Tortosa (concretament la de la Terra Alta), des de l'ínici fins a la fi del recorregut. 


\section{OBJECTIUS FONAMENTALS D'AQUEST ITINERARI}

Els objectius fonamentals que es pretenen aconseguir en aquest itinerari, es poden concretar en els següents aspectes generals:

1.- Observació i descripció dels materials terciaris (de l'Eocè i de l'Oligocè) de la Depressió Geològica de l'Ebre, que pertanyen majoritàriament al complex al-luvial de Gandesa - Horta de Sant Joan, que inclou, entre altres a la Formació Montsant i a la Formació Flix. Aquests materials, els veurem primer entre Horta de Sant Joan i Bot. Cal dir que bona part d'aquesta zona, s'inclou dintre del denominat Avant-país, situat al contacte entre la Depressió Geològica de l'Ebre i la Serralada Ibèrica.

2.- Observació a distancia i dels materials mesozoics (del Triàsic, del Juràssic i del Cretàcic) i dels cenozoics (de l'Eocè i de l'Oligocè), que constitueixen la Serralada Prelitoral Catalana.

2.- Observació a distancia i dels materials mesozoics (del Triàsic, del Juràssic i del Cretàcic), que constitueixen la Serralada Ibèrica. Nosaltres hi transitarem molt prop a l'inici del recorregut, prop d’Horta de Sant Joan.

4.- Observació de les estructures locals d'aquestes unitats geològiques acabades d'esmentar, que trobarem al llarg del recorregut de l'itinerari, i de les relacions existents entre elles. Així, ens referirem a les següents:

4A) a l'estructura de Branca Externa de la Serralada Prelitoral Catalana (integrant del Sistema Mediterrani), que trobarem a diferents trams del recorregut. En molts indrets, aquests es troben prop de la seva Zona d'Enllaç amb el Sistema Ibèric.

4B) de l'estructura de la Depressió Geològica de l'Ebre, que veurem als primers i als darrers trams del recorregut.

4C) de les relacions existents entre les unitats i sotsunitats geològiques acabades d'esmentar.

5.- Observació i reconeixement de diferents mineralitzacions situades a diferents indrets del recorregut de l'itinerari.

6.- Observació de les antigues explotacions mineres relacionades amb les mineralitzacions anteriors. Al respecte, cal dir que totes elles es troben actualment aturades. I alhora, si s'escau: observació i anàlisi dels impactes produïts sobre el Medi Natural (i sobre el Medi Ambient), tant per les explotacions mineres anteriors, com per altres activitats humanes.

7.- Observació dels diferents indrets relacionats amb el Patrimoni Geològic i Miner, que trobarem al llarg del recorregut..

\section{ANTECEDENTS BIBLIOGRÀFICS}

Pel que fa al recorregut del present itinerari, existeixen alguns antecedents molt propers, obra del mateix autor del present itinerari. Es tracta de MATA-PERELLÓ (1996b, 1997, 2000a, 2000b, 2001a, 2001b, 2005 i 2007). Un altre antecedent parcial, obra del 
mateix autor, es troba a MATA-PERELLÓ (1989), i correspon a un altre itinerari. Tanmateix, cal fer esment del treball de MATA-PERELLÓ i MONTANÉ GARCÍA (2006a i 2006b), en un itinerari fora semblant al present.

Pel que fa a la descripció de les mineralitzacions d'aquesta comarca, farem esment d'un altre treball del mateix autor, de MATA-PERELLÓ (1991), relatiu a les mineralitzacions catalanes en general. Uns altres antecedents, cal situar-los en MATAPERELLÓ (1995a i 1995b), relatius als inventaris mineralògics de les comarques de la Terra Alta i del Matarranya.

I, finalment, pel que fa a l'estructura geològica de la zona per la qual discorre l'itinerari, farem esment dels treballs de GUIMERÀ et altri (1982) i de RIBA et altri (1976). També, i dintre d'aquest apartat, també farem esment de diversos treballs de l'IGME (1972). Tots ells són relatius a diversos fulls geològics corresponents als indrets per on passarà el recorregut de l'íitinerari.

Tots aquests treballs referenciats, i d'altres, figuren esmentats per ordre alfabètic a l'apartat dedicat a la BIBLIOGRAFIA.

\section{RECORREGUT DE L'ITINERARI}

El recorregut de l'itinerari començarà dintre de la comarca de la Terra Alta, concretament a la població d' Horta de Sant Joan, per on es faran diverses aturades, prop de la població.

Després, caldrà arribar fins a la propera població de Bot, per on finalitzarà el recorregut d'aquest itinerari.

\section{DESCRIPCIÓ DE L'ITINERARI}

Com de costum, estructurarem el recorregut de l'itinerari en una sèrie de PARADES, que tot seguit anirem veient. En cada una d'aquestes aturades farem un breu comentari (geològic o mineralògic, segons s'escaigue).

Cada una d'aquestes parades tindrà un número, i un topònim representatiu. Per d'altra banda, s'indicarà el nom del poble més proper, el municipi al qual pertany l'indret, $\mathrm{i}$ la comarca on es troba situat. Per d'altra banda, també indicarem en cada cas, i entre parèntesi, el full topogràfic on es troba l'aturada.

Finalment, cal dir que el recorregut de l'itinerari s'inclourà dintre dels següents fulls, del "Mapa Topográfico Nacional", realitzats a l'escala 1:50.000 per 1'"Instituto Geográfico y Catastral": 470 (dit de Gandesa), 471 (dit de Reus) i 496 (dit d’Horta de Sant Joan).

Així doncs, la relació de parades ordenades, que composen aquest itinerari geològic i mineralògic, és el següent: 
PARADA 1. BARRANC DEL SALT, ROQUES DE BENET, (terme municipal d’Horta de Sant Joan, comarca de la Terra Alta). (Full 496).

El recorregut 1'iniciarem a Horta de Sant Joan, tot fent una fillola cap al Sud, anant cap a les immediacions de les Roques de Benet. Per anar-hi, ens caldrà arribar fins a la cruilla de les carreteres de Prat de Compte i Vall-de-roures. Des de la cruïlla, cal seguir per la carretera que va als Estrets, fins arribar al peu de les Roques de Benet, on caldrà fer la present parada, després d'un recorregut proper als $5 \mathrm{Km}$ des de la sortida a Horta de Sant Joan.

En aquest recorregut, des d'Horta de Sant Joan, s'han tallat els materials terciaris, que tornen a ésser majoritàriament de la Formació Flix. Més endavant s'ha passat a la Serralada Prelitoral Catalana, que aquí es troba encavalcant als anteriors materials, fet que no succeeix en altres indrets propers. Els materials que constitueixen aquesta serralada són eminentment calcaris, i pertanyen al Juràssic i al Cretàcic. També cal dir que aquest sector de la serralada forma part de la Zona d'Enllaç amb el Sistema Ibèric.

Per sobre d'aquests materials mesozoics acabats d'esmentar, es troben uns interessants afloraments dels nivells detrítics dels trams superiors de la Formació Montsant (que com ja s'ha dit, aquí forma part del Complex al-luvial de Gandesa-Horta de Sant Joan). Aquests materials són lleugerament posttectònics, tot i que es troben lleugerament deformats per des darreres convulsions. FOTOGRAFÍA 1.

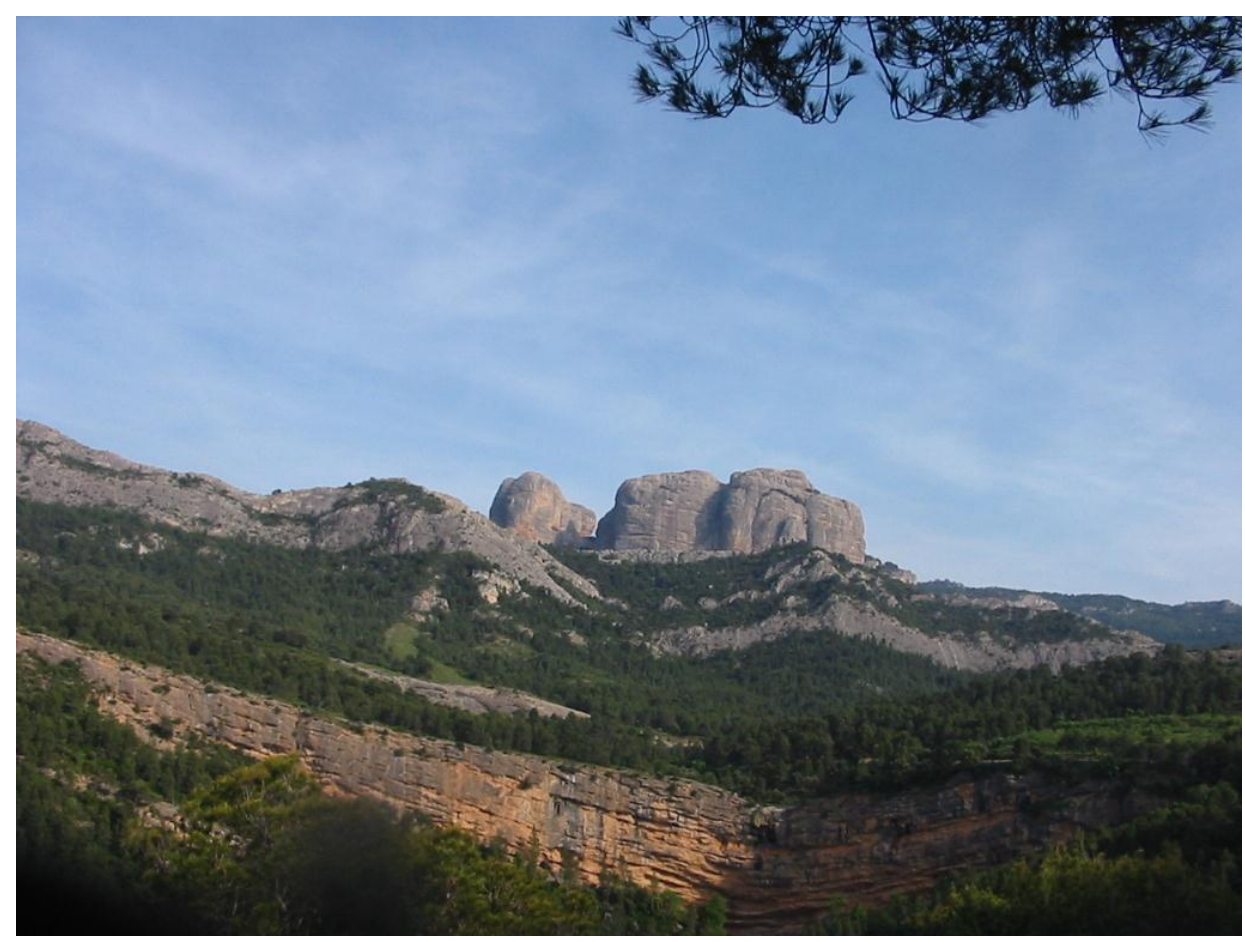

FOTOGRAFIA 1

Les Roques de Benet

A la part superior afloren nivells de conglomerats postorogènics.

A la part inferior hi ha un aflorament dels materials carbonatats mesozoics

Un esquema d'aquestes estructures és el següent: 


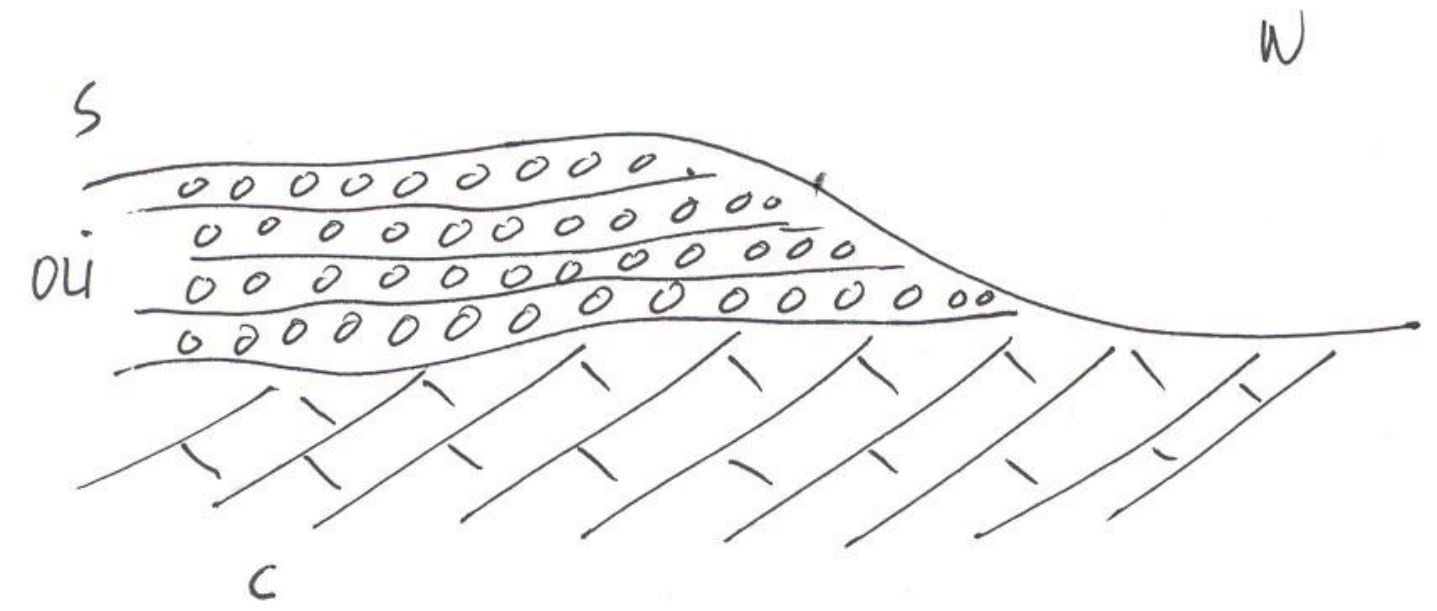

PARADA 2. SORTIDA D'HORTA DE SANT JOAN CAP A GANDESA CEMENTIRI, (terme municipal d'Horta de Sant Joan, comarca de la Terra Alta). (Full 496).

Després de realitzar la parada anterior, cal retornar a la població d Horta de Sant Joan, per tal de sortir per la carretera local que es dirigeix cap a Bot i cap a Gandesa. A la mateixa sortida, caldrà fer la segona aturada del recorregut.

En tot aquest breu recorregut, s'han continuat tallant els nivells de la Formació Montsant; força detrítics. Aquests materials formen part del rebliment de la Depressió Geològica de l’Ebre, per on ara estem situats.

Des d'aquest lloc, es pot gaudir d'una bona panoràmica de de la Mola de l'Ermita, amb el Convent de Sant Salvador, i l'Ermita de Sant Pau. La mola es troba situada sobre els materials de la Formació Montsant (els quals es troben molt inclinats cap al Nord), constituint una clara discordança progressiva; tot i essent alhora discordants amb els propers nivells cretàcics de la Serralada Prelitoral Catalana, situats al Sud de la mola que ara veiem.

PARADES 3 - 4. PARTIDA DE SOLANS, (terme municipal d'Horta de Sant Joan, comarca de la Terra Alta). (Full 496).

Des de la parada anterior, cal anar cap a Bot, per la carretera T-334. Després d'un recorregut proper als $2 \mathrm{Km}$, en arribar a l'indret de la Partida Solans, caldrà agafar un camí que surt per la dreta. A través d'aquest camí caldrà fer dues aturades: una a l'inici del camí i l'altra una mica més lluny (a uns 150 metres de l'inici).

En el recorregut entre la parada anterior i Horta de Sant Joan hem continuat trobant els materials esmentats anteriorment a les parades anteriors. Així, prop de la carretera hem seguit veient els materials verticalitzats, de la Formació Montsant, els quals s'ubiquen dintre de la Depressió Geològica de l’Ebre.. 
Per d'altra banda, en el recorregut, des del trencall d'Horta de Sant Joan s'han anat tallant els nivells lutítics i gresencs de la Formació Flix (la qual forma aquí part del Complex al-luvial de Gandesa - Horta de Sant Joan).

A l'indret de la parada (PARADA 3), i molt a prop de la carretera, es poden trobar interessants mostres de GUIX FIBRÒS (amb gruixos de 10-15cm). Aquests guixos són sempre secundaris i es troben entre els nivells de la Formació Flix. aquest guix es troba reblint diàclasis, i plans d'estratificació alhora.

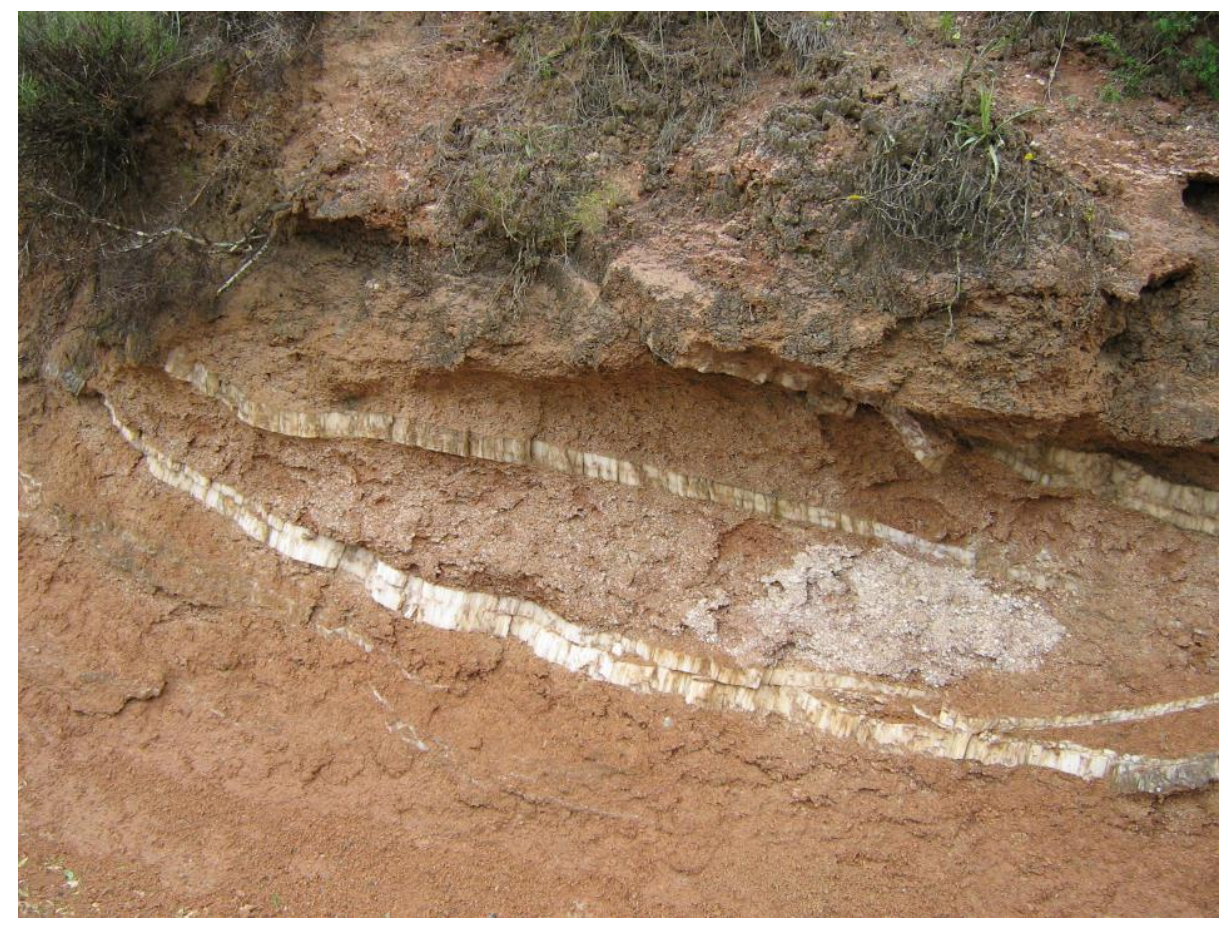

FOTOGRAFIA 2

Aspecte del guix fibrós

D'aquest indret, es poden observar, mirant cap al Nord (i NNW), uns interessants paleo-canals, desenvolupats entre els materials de la ja reiteradament esmentada Formació Flix. Cal dir que tots aquests materials, es troben inclinats amb una clara vergència septentrional. Es de destacar que aquets paleocanals són més abundants cap al SE que cap al NW, pel fet de trobar-se prop de la zona més detrítica, on aflora amplament la Formació Montsant.

Després, caldrà fer un recorregut a peu, proper als 150 - 200 metres, per fer una nova parada (PARADA 4).. Des d'aquest lloc, i continuant a peu pel camí, tot mirant cap a llevant, es pot veure una interessant discordança progressiva entre els materials de la Formació Montsant, que alhora es troben en contacte discordant amb els nivells calcaris de la Serralada Prelitoral Catalana.

Aquest es un bon indret, per tal d'observar l'estructura de la Serralada Prelitoral Catalana. FOTOGRAFIA 3. 


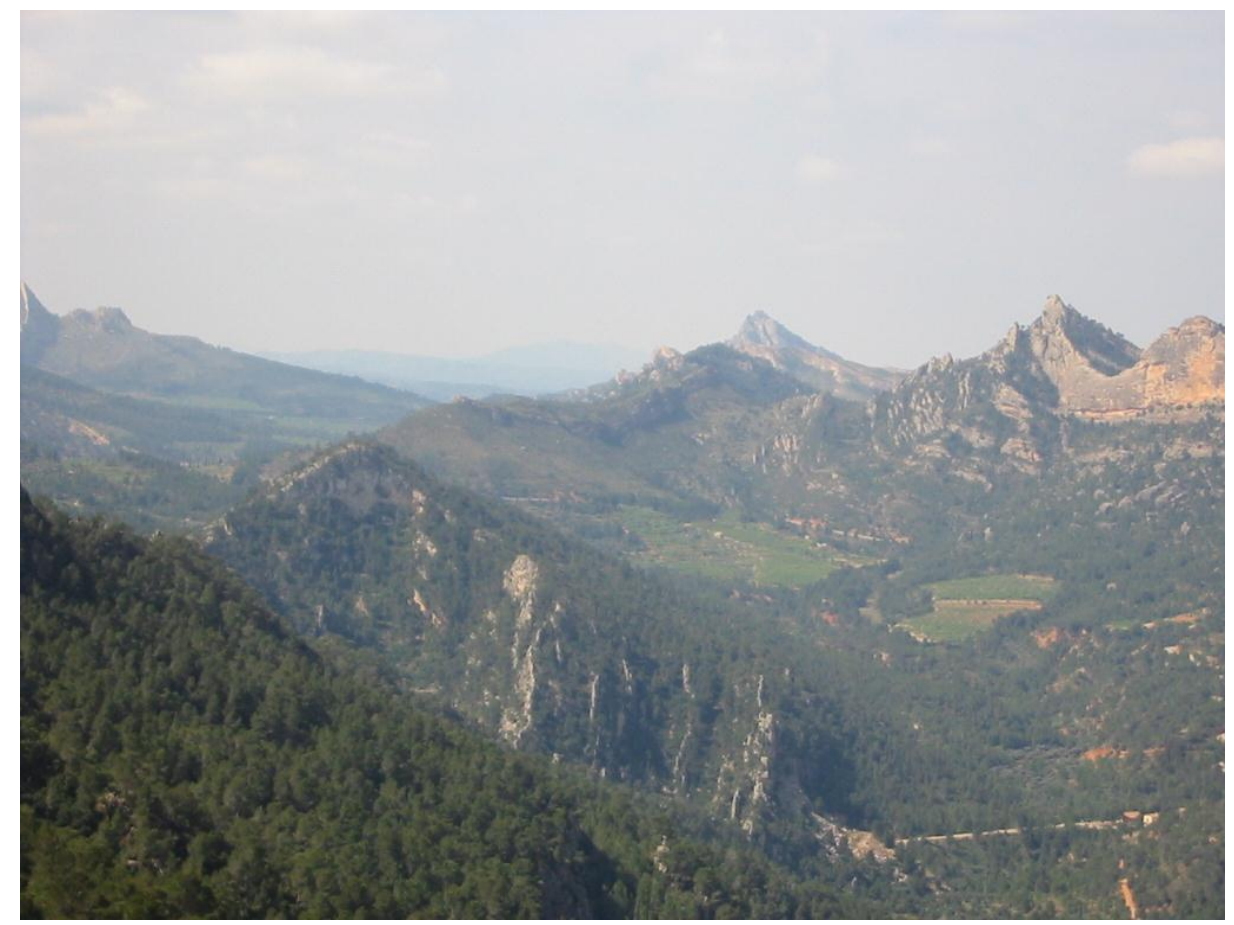

FOTOGRAFIA 3

Contacto entre la Serralada Prelitoral Catalana i la Depressió Geològica de l'Ebre Discordança progressiva de Bot - Horta de Sant Joan

PARADA 5 - CONDICIONAL. CARRETERA DE BOT A PRAT DE COMPTE, (terme municipal de Bot, comarca de la Terra Alta). (Full 470).

Després de fer l'aturada anterior, cal seguir cap a Bot i posteriorment cap a Prat de Compte, per la carretera que uneix les dues poblacions. Així, després sobrepassar Bot, farem una aturada a uns $2 \mathrm{Km}$ del poble i a uns $10 \mathrm{Km}$ de la parada anterior.

Al respecte, cal dir que tot el recorregut s'ha efectuat per la Depressió Geològica de l'Ebre, molt a prop del contacte amb la Serralada Prelitoral, per la denominada Zona d'Enllaç amb el Sistema Ibèric. També cal recordar que l'esmentada serralada es troba al SE, al Sud i al SW d'on som.

Els afloraments d'aquesta formació, es troben constituits per nivells de calcolutites ocres $i$ de gresos, del mateix color, clarament continentals. Cal destacar la presencia de trams conglomeràtics. En aquest sentit destaca el relleu de l'Agulla de Bot

\section{EN AQUEST INDRET FINALITZA EL RECORREGUT}

\section{REFERÈNCIES BIBLIOGRÀFIQUES}

GUIMERÀ, J. et altri (1992).- Geologia (II), Història Natural dels Països Catalans, Vol.2, 547 pag. Enciclopèdia Catalana, S.A. Barcelona 
IGME (1974).- Mapa Geológico de España a escala 1:200.000. Sintesis de la Cartografia existente. Hoja y memória no .41 (Tortosa). Inst. Geol. Min. España. Minist. Indústria. Madrid

MATA-PERELLÓ, J.M. (1989).- Una recerca mineralògica per les terres de l'Ebre: del Matarranya al Priorat. But. Col. Ofi, de Doctors i Llicenciats, nº 67, 15pag. Barcelona

MATA-PERELLÓ, J.M. (1991).- Els Minerals de Catalunya. Arxius de la Secció de Ciències, t. XCIII, 442 pag. Institut d’Estudis Catalans. Barcelona

MATA-PERELLÓ, J.M. (1995a).- Inventari Mineralògic de la comarca de la Ribera d'Ebre, Terra Endins, nº 9, 23 pag. Manresa

MATA-PERELLÓ, J.M. (1995b).- Inventari Mineralògic de la comarca de la Terra Alta, Terra Endins, ${ }^{\circ}$ 10, 22 pag. Manresa

MATA-PERELLÓ, J.M. (1996).- Itinerari geològic i mineralògic entre Gandesa, la Fontcalda i Vall-de -roures. Inèdit., 12 pàgines. Manresa

MATA-PERELLÓ. J.M. (1997).- Recerca geològica i mineralògica per les comarques de la Terra Alta i del Matarranya: des de Gandesa a Bot i Horta de Sant Joan, i des de Vall-de-roures a Fondespatlla. Inèdit, 17 pàg. Manresa

MATA-PERELLÓ. J.M. (2000a).- Recerca geològica i mineralògica per les comarques de la Terra Alta i de la Ribera de 1'Ebre: des de Pinell de Brai i Prat de Compte a Gandesa i a Mora d’Ebre. Algeps, sèrie B, $\mathrm{n}^{\mathrm{o}} 171,14$ pàg. Manresa

MATA-PERELLÓ. J.M. (2000b).- Recerca geològica i mineralògica per les comarques de la Terra Alta i del Matarranya: des de Gandesa a Vall-de-roures i a Fondespatlla. Algeps, sèrie B, $\mathrm{n}^{\mathrm{o}}$ 176, 18 pàg. Manresa

MATA-PERELLÓ. J.M. (2001a).- Recorregut de recerca geològica i mineralògica per les comarques de la Ribera d’Ebre i de la Terra Alta: des d'Ascó a Pinell de Brai, i des de Prat de Compte a Horta de Sant Joan, Inedit, 18 pàg. Manresa

MATA-PERELLÓ. J.M. (2001b).- Recorregut de recerca geològica i mineralògica per les comarques de la Terra Alta i del Matarranya: des d'Horta de Sant Joan a Vall-de-roures i a Fontespatlla Inèdit, 18 pàg. Manresa

MATA-PERELLÓ, J.M. (2005).- Recorreguts per la comarca de la Terra Alta: des del Pinell de Brai, a Prat de Compte i a Horta de Sant Joan. Inèdit. 12pag. Manresa

MATA-PERELLÓ, J.M. (2007).- Recorreguts per les comarques de la Terra Alta, Ribera d’Ebre i Priorat: des d’Horta des d’Horta de Sant Joan a Bot, Gandesa, Ascó, García, el Molar, Falset, Pradell i el Coll de la Teixeta. Inèdit. 18 pag. Manresa

MATA-PERELLÓ. J.M. i HERRERA SANCHO, J.A. (2001).- Recorregut de recerca geològica, mineralògica i naturalístiques pels Ports Inèdit, 18 pàg. Manresa

MATA-PERELLÓ, J.M. i MONTANÉ GARCÍA, P. (2006).- Recorregut geològic i mineralògic per la comarca de la Terra Alta: des de Gandesa a Prat de Compte, a Horta de Sant Joan i a Arnés. Inèdit, 12 pag. Manresa

RIBA, O. et altri (1976).- Geografia Física dels Països Catalans, Edit. Ketres, 254 pàgines. Barcelona. 